EASTERN REVIEW 2019, T. 8

\author{
Alena Artsiomenka \\ (iD) https://orcid.org/0000-0003-3162-1363 \\ Belarusian State University, Minsk, Belarus \\ Faculty of Philosophy and Social Sciences \\ Department of Social Communication \\ e-mail: lena.artsiomenka@gmail.com
}

\title{
The transformation of family values in Belarus: Social and demographic factors
}

\begin{abstract}
The article is devoted to the social and demographic factors of family values transformation in Belarus. It aims to find out to what extent age, educational level, and place of residence influence the dynamics of changing family values. Based on the data of the European Value Survey in Belarus in 2000, 2008 and 2017, the tendencies of the transformation of attitudes towards family, marriage, children, and women combining family and profession roles, are analysed. It is concluded that changes in family values in the Eastern European region and Belarus are multidirectional. On the one hand, the significance of the family and marriage is growing. On the other - the necessity to combine the professional and family roles of women is getting more common. The paper evaluates how these general trends are manifested in different social groups; broken down by age, education level and place of inhabitance. The analysis allows one to conclude that there are universal trends like the importance of family as it is. However, some trends like pronatalist attitudes have specificity for different groups. The reasons for family values transformation include the position on the labour market, the perspective of professional self-realisation, and income growth. A lack of such a perspective among women with secondary education causes them to be more focused on family and children. Both urbanisation and the growth of a young generation with a high educational level can contribute to the decrease of pronatalist attitudes and an increase in the idea of women combining family and professional roles in the future.
\end{abstract}

Keywords: values transformation, family, marriage, children, gender, Belarus. 


\section{Introduction}

In Belarusian society, as in other European countries, the institution of the family continues to undergo changes. While the family remains very significant, as "a basic vital value" (Burova, 2015: 4), the stability of family relationships is decreasing. The markers of this process are the increasing age at which people get married and have children; the high divorce rate, and the decreasing fertility. In 2017 the number of divorces in Belarus amounted to $48.3 \%$ of marriages (the marriage rate constituted 7.0 marriages per 1,000 inhabitants while the divorce rate was 3.4 divorces per 1,000 inhabitants). It is often the case that families with children were broken up as a result. In 201713.6 thousand (42.5\%) divorces happened in families without children; however, 13.4 thousand divorces $(41.9 \%)$ occurred in the families with one child. When it comes to the attitude of having children, in the long-term perspective, the fertility rate is decreasing. While in the mid-1980s the total fertility rate in Belarus exceeded 2 childbirths per woman, in 2017 the index constituted only 1.54 childbirths (Medvedeva ed., 2018). All the listed tendencies which can be described with the concept of the second demographic transition pertain to Belarus as well (Lapeto et al., 2018: 21).

To understand the process of change in the family institution we need to analyse the transformation of family values: if the family continues to be the basic social unit, what is the perception of marriage and childbearing? What are the attitudes towards the relationship between family members? Many of these trends affect not only one country but the whole region, as "not only personal but even moral and civilisational changes are occurring through the family" (Titarenko, 2004: 77).

The comparative analysis of the transformation of values on a European and global level is possible with the support of the empirical database of the World Values Survey and European Values Study (WVS/EVS) which have been carried out since 1981 in 97 countries of the world. The methodology of WVS/ EVS enables us to analyse (in both a synchronic and diachronic perspective) such components of the family value system as the perception of a family as a value in general; attitudes to marriage; childbearing; and one other important feature of family relationships: the perception of the combining of professional and family roles by women as an important marker of the modernity of the views.

The world data of the surveys from 1988-2005 allows the researchers to come to the conclusion that value changes all over the world can be described by the common patterns of: 1) from traditional to secular-rational values; and 2) from survival to self-expression values. Movement along the first axis is connected to the weakening of such important traditional values as the significance of the family as a social institution, while movement along the second axis is associated with the strengthening of gender equality (Inglehart, Norris, 2003: 11). 
However, the transformation of the value system in an individual country is determined by not only the general trends, but the cultural-historical context as well. As noted by the authors of the research, Belarus belongs to the group of countries with a common Communist past and with a prevalence of the Eastern Orthodox Church. Analysing the tendencies of value transformation in this group of countries, the researchers noted that after 1991 values were changing in this region in the direction towards traditional religious values, contrary to the general world trend; this in turn also influenced the attitudes towards the family (Inglehart, Oyserman, 2004: 88).

The analysis of changes in family and the marital values depicted in the data of WVS/EVS in 1990-2000 (carried out by L. Titarenko in the monograph The value world of the contemporary Belarusian society. Gender aspect) shows that, as the result of the controversial trends described above, the values of Belarusians are forming as a métissage system "in which traditional and contemporary views are of equal importance" (Titarenko, 2004: 104). However, women are both carriers of distinctly patriarchal views, and advocates of the equal distribution of duties in the family at the same time. The monograph prepared by the researchers of the Centre for Sociological and Political Studies at the Belarusian State University "The value world of today's people: Eastern Partnership countries, European Union and Russia in international projects on value studies" is focused on the cross-country comparison of values (Bulynko et al., 2016). To understand what Belarusians' positions concerning the family are, the authors conducted cluster analysis using the key factors of family values. According to the result, Belarus belongs to the group of countries with a distinguished pronatalist component, yet with the lowest level of family significance and matrimonial traditionalism. Generally, the analysis shows the differences between the value systems in the Eastern Partnership countries and the European Union member states.

Sociologists in neighbouring countries pay close attention to the result of the research in cross-country comparisons as well. Analysing the family values in Russia according to the result of the WVS/EVS in 2008, the authors of the article Family values of Russians and Europeans came to the conclusion that, "Russia is a country with a medium to high level of traditionalism of the reported normative views." Moreover, as we saw in Belarus the most conservative position is reported with regard to having children. However, at the same time, there were signs of a liberalisation of views, such as a more liberal attitude towards homosexuality (Fabrikant, Magun, 2014). In the article Differences and similarities: the place of religion and family in the value system of society in Poland, The Czech Republic and Slovakia, the family values analysis of Belarus's western neighbours is presented (Swadźba, 2015). The author concluded that religion is more important for Polish people than for Czechs and Slovaks, and this influences attitudes towards family and marriage, meaning that they are also more traditional. However, it is remarkable that youth is more liberal in its views and less inclined to religion in all the analysed countries and this corresponds to the general trend of values modernisation. 
The last wave of WVS/EVS data in Belarus in 2017 confirms the previous conclusions. Nowadays the dynamics of Belarusians' family values is continuing the tendency noted above. On one hand, the importance of the family continues to grow (in $200078.5 \%$ answered very important, in 2017 the share was 89.4\%) as in Poland, Russia and Ukraine (the trend in Latvia and Lithuania is the opposite). Also, an increasing number of people in Belarus think that it is an obligatory duty towards society to have children (from $20.1 \%$ in 2008 to $25.3 \%$ in 2017), as in Poland and Russia. On the other hand, marriage is more rarely perceived as necessary for happiness (in $200034.6 \%$ agreed with the statement, while in 2008 only $28.0 \%$ agreed), as in Poland, Lithuania and Latvia (the trend in Russia and Ukraine is opposite). Moreover, fewer and fewer people in Belarus agree that it is enough for women just to stay home with children to be happy (the share decreased from $31 \%$ in 2000 to $15.7 \%$ in 2017), as in Russia and Poland as well (Artsiomenka, 2019). Thus, we can see that there are similarities and differences in the dynamics of the value system in Belarus and neighbouring countries, and some trends in Belarus strengthen traditional views (like the general attitude towards family and the perception towards childbearing), but some of them are modern (like the perception of the combination of both family and professional roles for women).

However, there arises the question of whether the value system in Belarusian society is heterogeneous; as tendencies with regards to changing values could differ from one social group to another. To understand the process of value transformation deeper it is important to uncover what socio-demographic factors can influence the dynamics. Thus, the objective of the current work is to investigate the difference in the transformation of the values system between different groups, based on age, education level and place of inhabitance. It is important to ascertain whether the trends are universal, or there is a specific character for different social groups. The answer to this question could enable us to understand some reasons for value transformation, as well as to assume what changes we can expect in the future. In this paper, as a benchmark for family values dynamics, we use the perception of the family as a value in general: the view that marriage is as outdated social institution; the belief that childbearing is an obligatory duty towards society; and the opinion, that work is important but women really want to stay at home with children.

\section{Age as a factor of value transformation}

The first social characteristic we consider as a very important factor for the transformation of family values is age. Traditionally younger generations are perceived as carriers of the modernisation of views; however, in the case of controversial trends in the transformation of Belarusian values, the result may not be so obvious. When the last wave of the study is analysed, most people in every 
age group consider family as a very important value; although, the older the age the stronger this attitude is. According to the analysis in the neighbouring countries we mentioned above, this rule is typical for all of them as well. The difference between the youngest group (15-24 years old) and the oldest one (65+ years old) is more than $10 \%(77.3 \%$ vs. $88.6 \%)$. However, the trend is common: every group demonstrates the strengthening of the attitude.

Table 1. The distribution of answers to the question: How important is the following value in your life? Family (response rate of "Very important" by age group), \%

\begin{tabular}{|c|c|c|c|c|c|c|}
\hline Year & $\mathbf{1 5 - 2 4}$ y.o. & $\mathbf{2 5}-\mathbf{3 4}$ y.o. & $\mathbf{3 5 - 4 4}$ y.o. & $\mathbf{4 5 - 5 4}$ y.o. & $\mathbf{5 5 - 6 4}$ y.o. & 65+ y.o. \\
\hline 2000 & 73.4 & 82.9 & 84.5 & 81.1 & 83.1 & 64.3 \\
\hline 2008 & 79.1 & 80.3 & 85.3 & 87.4 & 79.4 & 76.9 \\
\hline 2017 & 77.3 & 89.5 & 91.1 & 88.9 & 93.9 & 88.6 \\
\hline
\end{tabular}

Source: based on author's calculations.

When we look at different components of the family in detail, we discover that there is not such a uniform situation. The share of people who believe that marriage is an outdated social institution is bigger among younger people than among older people (from $27.1 \%$ in the group of $15-24$ years old to $8.3 \%$ in the group of $65+$ years old); however, among the younger groups, we observe a decreasing popularity of the statement, while in groups of 55-64 years old and 65+ years old we can see the increasing popularity of the statement. Sure, the difference is too small to state that it is statistically significant, but the trend is obvious. To understand why social groups which are usually more traditional in their views demonstrate such a difference in the dynamics we have to discuss what they mean when they talk about family as an outdated institution. Our assumption is that they are more critical in the perception of the current transformation of marriage and its functions nowadays (e.g. the changing focus from duty and childbearing to personal relations and emotions; a different distribution of family roles etc.). This is why they can perceive the transformation as a kind of perversion. However, this assumption needs to be checked with further studies.

Table 2. The distribution of answers to the question: Do you agree with the statement, that marriage is an outdated social institution? (response rate of "Agree" by age group), \%

\begin{tabular}{|c|c|c|c|c|c|c|}
\hline Year & 15-24 y.o. & $\mathbf{2 5 - 3 4}$ y.o. & 35-44 y.o. & 45-54 y.o. & 55-64 y.o. & 65+ y.o. \\
\hline 2000 & 31.0 & 21.7 & 18.2 & 14.0 & 9.4 & 5.5 \\
\hline 2008 & 23.7 & 21.8 & 19.0 & 15.4 & 16.1 & 12.0 \\
\hline 2017 & 27.1 & 18.4 & 17.6 & 12.3 & 11.2 & 8.3 \\
\hline
\end{tabular}

Source: based on author's calculations. 
Speaking about childbearing, the respondent's age is important from the point of view of the life cycle stage which people are experiencing at the moment. The average age at which a woman has her first child in Belarus is 27 years old (Medvedeva, 2018). Thus, the youngest group of 15-24 years old has not realised their reproductive needs yet, most probably. This can be the reason, why the growing trend of people who are sure that it is their duty towards society to have children is not a characteristic of this group. The share of those who agree strongly with the statement in the group of 15-24 years old decreased from $19.7 \%$ in 2008 to $10.4 \%$ in 2017. However, as we see in the case of general attitudes towards the family, the younger people are, the less traditional views they have. Thus, the difference in the dynamics of the perception of childbearing among youth can be the beginning of a new trend for the whole society.

Table 3. The distribution of answers to the question: Do you agree with the statement, that it is a duty towards society to have children? (response rate of "Agree strongly" by age group), $\%$

\begin{tabular}{|c|c|c|c|c|c|c|}
\hline Year & 15-24 y.o. & $\mathbf{2 5}-\mathbf{3 4}$ y.o. & $\mathbf{3 5}-\mathbf{4 4}$ y.o. & $\mathbf{4 5}-\mathbf{5 4}$ y.o. & $\mathbf{5 5}-\mathbf{6 4}$ y.o. & $\mathbf{6 5 +}$ y.o. \\
\hline 2008 & 19.7 & 15.4 & 16.3 & 21.3 & 23.0 & 29.0 \\
\hline 2017 & 10.4 & 18.1 & 20.3 & 29.0 & 32.0 & 36.1 \\
\hline
\end{tabular}

Source: based on author's calculations.

As we mentioned above, younger people have more modern views, and this is true for the perception of women combining family and professional roles. However, the trend is universal, and all the age groups demonstrate a decrease in the degree to which they agree that it is enough for a woman just to be at home with children. In 2017 the difference in the position of the youngest group, 15-24 years old, and the oldest group, 65+ years old, was only 5.5\%.

Table 4. The distribution of answers to the question: Do you agree with the statement, that work is important, but women really want a home and children? (response rate of "Agree strongly" by age group), $\%$

\begin{tabular}{|c|c|c|c|c|c|c|}
\hline Year & $\mathbf{1 5}-\mathbf{2 4}$ y.o. & $\mathbf{2 5}-\mathbf{3 4}$ y.o. & $\mathbf{3 5}-\mathbf{4 4}$ y.o. & $\mathbf{4 5}-\mathbf{5 4}$ y.o. & $\mathbf{5 5 - 6 4}$ y.o. & $\mathbf{6 5}+$ y.o. \\
\hline 2000 & 26.3 & 32.0 & 27.7 & 31.2 & 37.3 & 43.7 \\
\hline 2008 & 15.3 & 13.2 & 17.9 & 19.4 & 20.8 & 18.6 \\
\hline 2017 & 8.5 & 14.1 & 19.5 & 13.8 & 20.1 & 14.0 \\
\hline
\end{tabular}

Source: based on author's calculations.

Thus, we can see that the general trend of the traditionalization of some views is typical for all age groups. The research in neighbouring countries shows, that the youth typically have more modern views for all the questions, with the exception of attitudes towards abortion: the youngest groups in Poland and 
Slovakia demonstrated a lower tolerance to abortion than people of middle age (Swadźba, 2015: 116). However, speaking generally, the latest data proves the previous conclusions that the younger people are, the more modern views they have. However, there are some interesting observations about the age groups to think about. In the youngest group of Belarusians, we can see a change of the general trend towards the increasing number of those who are sure that it is everybody's duty to have children; this could be a sign that the pronatalist tendency may change in the nearest future. The second interesting finding is that the oldest people more often think that marriage is an outdated institution. Our assumption is that such answers stem from the fact that their attitudes towards marriage differ from contemporary forms of family relations, that is why their view is more and more critical. However, both assumptions need further research.

\section{Education as a factor of value transformation}

The second parameter which is interesting for us in terms of the dynamics of the value system is the level of education. Education is very important for the socialisation process; also it can influence the circle of social contacts; preferred sources of information; as well as career ambitions and position on the labour market. In our comparative analysis, we are concentrating on the three largest groups of educational levels: just secondary education (25.9\%), post-secondary (not tertiary) education (31.5\%), and tertiary education (34.8\%), according to WVS/EVS data in 2017. The dataset contains comparable data on education levels only for the waves in 2008 and 2017, but this 10-year interval is enough to note the main tendencies.

As in the case of different age groups, it is a universal trend that the concept of family is given greater importance with the increasing course of time. That said, it should be noted that it is somewhat lower among those who have only secondary education and there is almost no difference between people with post-secondary and higher education.

Table 5. The distribution of answers to the question: How important in your life is the following value? Family (response rate of "Very important" by education), \%

\begin{tabular}{|c|c|c|c|}
\hline Year & Secondary education & Post-secondary education & Tertiary education \\
\hline 2008 & 77.9 & 85.0 & 85.5 \\
\hline 2017 & 87.2 & 91.2 & 90.1 \\
\hline
\end{tabular}

Source: based on author's calculations. 
In 2008, in the group of people with only secondary education, the statement that marriage is an outdated social institution was the most popular as well. However, in time the difference between groups was smoothed over, and the statement becomes less popular for all of the groups. Anyway, we can note that the group of people with the lowest educational level demonstrates less traditional views on the importance of the family and the relevance of marriage.

Table 6. The distribution of answers to the question: Do you agree with the statement, that marriage is an outdated social institution? (response rate of "Agree" by education), \%

\begin{tabular}{|c|c|c|c|}
\hline Year & Secondary education & Post-secondary education & Tertiary education \\
\hline 2008 & 22.7 & 19.2 & 15.3 \\
\hline 2017 & 15.3 & 16.2 & 12.2 \\
\hline
\end{tabular}

Source: based on author's calculations.

In the case of attitudes towards childbearing, we can see the opposite situation. People with the lowest education achieved the highest level of agreement with the necessity of children. In spite of the common trend of increasing pronatalist views, the perception of the necessity to have children is lower in the group of people with higher education than with secondary education ( $19.2 \%$ vs. $29.6 \%$ correspondently). The reasons can be different. The first one is that people with higher education could be less sensitive to the state rhetoric about the necessity to increase fertility because of the usage of a broader range of media and informational sources. However, in that case, we would see the same trend (less traditional views) regarding family and the perception of marriage. The second reason can be that people with tertiary education can have more ways for self-realisation, the perspective of carrier growth and higher income. The dynamics of pronatalist views in the group of higher education is much lower as well, that is why we can conclude, that increasing the education level among the population, in general, can lead to a decreasing of pronatalistic views in the future.

Table 7. The distribution of answers to the question: Do you agree with the statement, that it is a duty towards society to have children? (response rate of "Agree strongly" by education), \%

\begin{tabular}{|c|c|c|c|}
\hline Year & Secondary education & Post-secondary education & Tertiary education \\
\hline 2008 & 18.6 & 21.8 & 16.6 \\
\hline 2017 & 29.6 & 27.6 & 19.2 \\
\hline
\end{tabular}

Source: based on author's calculations.

The universal trend, in terms of different age groups, to welcome the combining of family and professional roles by women looks different when 
we analyse the level of education. In spite of the general tendency towards the modernisation of views, people with only secondary education in 2017 more often agree with the statement, that work is important but women really want a home and children. The reason for such dynamics can be the same as in the case of childbearing attitudes. Having fewer possibilities for career and self-realisation they agree that the family can be the central role in a woman's life. With a decreasing of the share of people with only secondary education, we can expect an even higher acceleration of positive attitudes towards the combining of family and professional roles by women.

Table 8. Distribution of answers to the question: Do you agree with the statement, that work is important but women really want a home and children? (response rate of "Agree strongly" by education), $\%$

\begin{tabular}{|c|c|c|c|}
\hline Year & Secondary education & Post-secondary education & Tertiary education \\
\hline 2008 & 16.5 & 17.8 & 13.9 \\
\hline 2017 & 19.2 & 14.9 & 12.9 \\
\hline
\end{tabular}

Source: based on author's calculations.

The analysis of views of people with different educational levels shows that the group with only secondary education is less traditional in the questions about the importance of family and the relevance of marriage. However, at the same time they are more traditional when it comes to childbearing; and even stand out against the general trend, starting to claim more often that it is enough for women to stay home and bring up children. We suppose that the reason for such a difference is in the narrower perspective of professional self-realisation, careers, and income growth, which makes them more focused on childbearing and family, even when their views are no more traditional than others.

\section{Settlement type as a factor of value transformation}

To understand the role of geographical factors in the process of values transformation we started from looking at the regional distribution of beliefs. However, as in many other cases in Belarus, the difference in value dynamics between the regions is not well defined, and the only remarkable distinction between Minsk as the capital and all the other territories can be explained by the difference in city size. That is why we focused on the settlement types according to the number of inhabitants. The WVS/EVS dataset allows the use of the classification which includes settlements with less than 5 thousand, 5-100 thousand, 100-500 thousand and 500+ thousand 
inhabitants. The smallest type includes most of the rural and several of the smallest urban settlements, while the largest type includes only Minsk and Gomel (the largest regional centre in Belarus, apart from the capital). All the other regional centres and 1-2 big cities in each region belong to the group of 100-500 thousand inhabitants. The WVS/EVS dataset from 2017 contains the following distribution by settlement size: $26 \%$ live in settles of under 5 thousand, $21.4 \%$ in settles of 5-100 thousand, $26.9 \%$ in settlements of $100-$ 500 thousand, and $25.6 \%$ in settlement of more than 500 thousand inhabitants, thus they have almost equal influence on the situation in general.

As for such a factor as the type of settlement, the growth in the importance of the family is a universal trend: there is no significant statistical difference related to the size of the settlement.

Table 9. The distribution of answers to the question: How important in your life is the following value? Family (response rate of "Very important" by settlement size), \%

\begin{tabular}{|c|c|c|c|c|}
\hline Year & Under 5,000 & $\mathbf{5 , 0 0 1 - 1 0 0 , 0 0 0}$ & $\mathbf{1 0 0 , 0 0 0 - 5 0 0 , 0 0 0}$ & $\mathbf{5 0 0 , 0 0 0 +}$ \\
\hline 2000 & 75.8 & 76.3 & 82.9 & 81.0 \\
\hline 2008 & 82.7 & 83.2 & 78.0 & 84.5 \\
\hline 2017 & 91.3 & 89.7 & 86.5 & 90.1 \\
\hline
\end{tabular}

Source: based on author's calculations.

However, the situation does not look so universal when we speak about the attitudes towards marriage. People consider marriage as an outdated institution less often in all the settlement types, apart from the smallest one. In $200016.1 \%$ of inhabitants of the smallest settlements perceived marriage as outdated, while in 2017 the share increased to $20.6 \%$. However, taking into consideration the relatively small sub-sample size, this difference is not statistically significant; but it is remarkable because in bigger settlements the trend is the opposite. This situation corresponds to the same characteristics of the oldest age groups. People in rural areas (the proportion of older people is higher there than in urban areas as well) could perceive the current changes in marriage more critically, that is why their answers differ from others'.

Table 10. The distribution of answers to the question: Do you agree with the statement, that marriage is an outdated social institution? (response rate of "Agree" by settlement size), \%

\begin{tabular}{|c|c|c|c|c|}
\hline Year & Under 5,000 & $\mathbf{5 , 0 0 1 - 1 0 0 , 0 0 0}$ & $\mathbf{1 0 0 , 0 0 0}-\mathbf{5 0 0 , 0 0 0}$ & $\mathbf{5 0 0 , 0 0 0 +}$ \\
\hline 2000 & 16.1 & 14.2 & 19.7 & 18.5 \\
\hline 2008 & 13.5 & 21.9 & 20.0 & 18.8 \\
\hline 2017 & 20.6 & 13.9 & 12.1 & 12.8 \\
\hline
\end{tabular}

Source: based on author's calculations. 
In the case of readiness to have children, the trend in the largest cities differs from others. While in smaller settlements, as in Belarus in general, we can speak about the obvious strengthening of pronatalist views; in the largest cities, we see some decrease of the share of people who believe that it is an obligatory duty to have children. This can be explained with many factors: from the younger age structure of the population in Minsk to a better situation on the labour market and lifestyle specificity. However, in any case, we can assume that the further urbanisation of Belarus will change the trend from a growing pronatalist orientation to the opposite.

Table 11. The distribution of answers to the question: Do you agree with the statement, that it is a duty towards society to have children? (response rate of "Agree strongly" by settlement size), \%

\begin{tabular}{|c|c|c|c|c|}
\hline Year & Under 5,000 & $\mathbf{5 , 0 0 1 - 1 0 0 , 0 0 0}$ & $\mathbf{1 0 0 , 0 0 0 - 5 0 0 , 0 0 0}$ & $\mathbf{5 0 0 , 0 0 0 +}$ \\
\hline 2008 & 21.5 & 19.4 & 18.0 & 22.5 \\
\hline 2017 & 29.8 & 25.5 & 25.4 & 20.3 \\
\hline
\end{tabular}

Source: based on author's calculations.

In the final component of family values that we observed (the attitudes towards combining family and professional roles by women) we saw a symmetry between inhabitants of different settlement types: that fewer people support the idea of women staying at home without professional self-realisation.

Table 12. The distribution of answers to the question: Do you agree with the statement, that work is important but women really want a home and children? (response rate of "Agree strongly" by settlement size), \%

\begin{tabular}{|c|c|c|c|c|}
\hline Year & Under 5,000 & $\mathbf{5 , 0 0 1 - 1 0 0 , 0 0 0}$ & $\mathbf{1 0 0 , 0 0 0}-\mathbf{5 0 0 , 0 0 0}$ & $\mathbf{5 0 0 , 0 0 0 +}$ \\
\hline 2000 & 37.7 & 30.1 & 27.9 & 31.9 \\
\hline 2008 & 15.9 & 19.4 & 16.3 & 17.8 \\
\hline 2017 & 22.4 & 18.2 & 9.7 & 12.9 \\
\hline
\end{tabular}

Source: based on author's calculations.

Thus, the settlement type is significant for some trends in the transformation of family values, but some of them are universal for all the territories. To the second group of universal tendencies we can allocate the perception of the importance of the family in general (a trend towards traditional values) and at the same time the growing popularity of women combining professional and family roles (a trend towards modern values). However, the settlement size is important in the case of attitudes towards marriage (in the smallest settlements it is perceived as an outdated institution more often), and in the case of the necessity to have children (in large cities there is a decreasing amount of agreement that it is a duty for everybody). 


\section{Conclusion}

The analysis of the influence of social-demographic factors on the transformation of family values we have conducted allows one to make the following conclusions:

1. In general, the younger people are, the more modern views they have; the same rule we can see in the case of settlement size (a bigger settlement is associated with less traditional views). That said, there is no such dependence in the case of groups with a lower or higher level of education.

2. Some of the trends are more or less universal, but some of them have specificity in the case of different social groups. The most universal trend for all the analysed social groups is the growing importance of the family, which is a sign of values traditionalization in the whole population.

3. Marriage is perceived as an outdated institution more rarely, and this is the sign of traditionalization as well. However, regardless of their more traditional views, older people and inhabitants of the smallest settlements are starting to think more often that marriage is an outdated institution. Probably, because of their personal traditional views on marriage differed from contemporary forms of family relations, their current views are getting more critical.

4. Over the course of their lives, people in Belarus become more supportive of pronatalist views. This is especially strongly pronounced in the group of people with just secondary education. The youngest group and inhabitants of the largest cities demonstrate the opposite trend. We assume that the growth of urbanisation may lead the youngest groups to changes that can stop the pronatalist tendency.

5. A strong attitude towards women combining family and professional roles distinguishes Belarusians from people in the neighbour countries; currently, it seems to be a universal trend for different age groups and type of settlements. At the same time, however, groups with secondary education demonstrate the opposite tendency: probably women in this group do not have a real possibility for professional self-realisation when they have a child, and they prefer to focus on the family.

6. Finally, we selected possible reasons for the transformation of family values. They include the position on the labour market, the perspective of professional self-realisation, and income growth. The more perspectives women have (especially in the largest cities), the fewer pronatalist views they express.

7. Both urbanisation and the growth of the education level among the current young generation could contribute to a decrease of pronatalist attitudes and an increase in the idea of women combining family and professional roles. Still, there are no visible signs to prove that family and marriage will be less important in the nearest future. 


\section{References}

Artsiomenka, A. 2019. Family values - the basis of sustainable development of the state. SOTIS - Social Technologies. Research 2, pp. 73-81.

Bulynko, D., Danilov, A., Pravdivets, V., Rotman, D. 2016. Value world of today's people: Eastern Partnership countries, the European Union and Russia in international projects on value studies. Minsk: BSU publishing house.

Burova, S. 2015. Modern family: failure or another reality? Sociology 2, pp. 4-15.

Fabrikant, M., Magun, V. 2014. Family values of Russians and Europeans. Demoscope Weekly 613-614, pp. 1-15.

Inglehart, R., Norris, P. 2003. Rising tide: gender equality and cultural change around the world. Cambridge: Cambridge University Press.

Inglehart R., Oyserman. 2004. Individualism, autonomy, self-expression. The Human development syndrome. In: H. Vinken, J. Soeters, P. Ester (eds.). Comparing cultures: dimensions of culture in a comparative perspective. Boston, MA: Brill.

Lapeto, A., Tereschenko, O., Shaverdo, T. 2018. Transition to adult life (age models of life trajectories). In: O. Tereschenko, T. Kutchera (eds.). Belarus: family structure, family relations, reproductive behaviour: Vol. II. Research outcomes analysis. Minsk: Belsens.

Medvedeva, I. ed. 2018. Demography yearbook of the Republic of Belarus. National statistical committee of the Republic of Belarus.

Swadźba, U. 2015. Różnice i podobieństwa: miejsce religii i rodziny w systemie wartości społeczeństwa polskiego, czeskiego i słowackiego. Górnośląskie Studia Socjologiczne. Seria Nowa 6, pp. 101-122.

Titarenko, L., 2004. World of values of modern Belarusian society: gender aspect. Minsk: BSU publishing house. 